\title{
Colonic varices as a result of persistent mesocolon of the ascending and descending colon
}

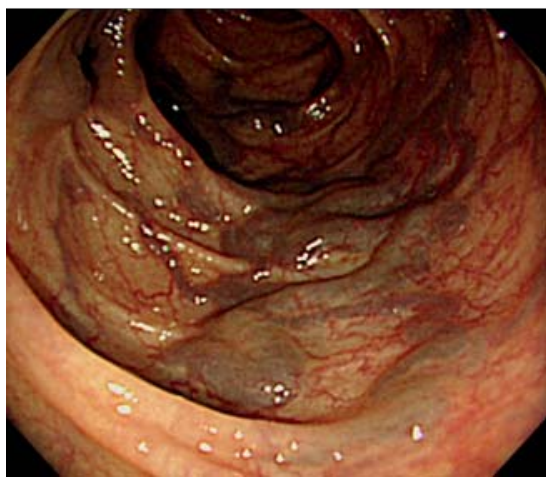

Fig. 1 View of the colonic varices obtained on colonoscopy.

A 49-year-old man had a 15-year history of slight melena, which had occurred once or twice a year. Colonoscopy during a health checkup revealed nodular, phyma-like, large varices in a $10 \mathrm{~cm}$ area involving the descending to sigmoid colon (๑ Fig. 1).

Neither flare nor hemorrhage was observed. Plain abdominal radiography showed colonic gas moving to the right (๑ Fig. 2).

Contrast-enhanced irrigoscopy revealed impairment of the colonic course. The continuity of a large number of polyp-like protrusions was observed in the descending colon region, which was consistent with the varices on endoscopy ( $\bullet$ Fig. 3 ). Upper-digestive-tract endoscopy did not show any abnormalities. Neither abdominal ultrasonography nor computed tomography (CT) revealed portal hypertension. To confirm the course and localization of the varices, CT angiography was performed. The stasis of venous blood flow was noted in the upper stream of the inferior mesenteric vein (IMV). The IMV flowed into the superior mesenteric vein (SMV) via flexion and/or displacement, confirming that venous congestion was consistent with the varix site shown by irrigoscopy ( $\bullet$ Fig. 4 ).

Seventy-five percent of colonic varices are regarded as portal-hypertension-related lesions. In addition, idiopathic varices, vascular malformation, familial varices, and compromise of mesenteric vein circulation (thrombosis, tumor, pancreatitis) have been reported [ $1-3]$. This is the first
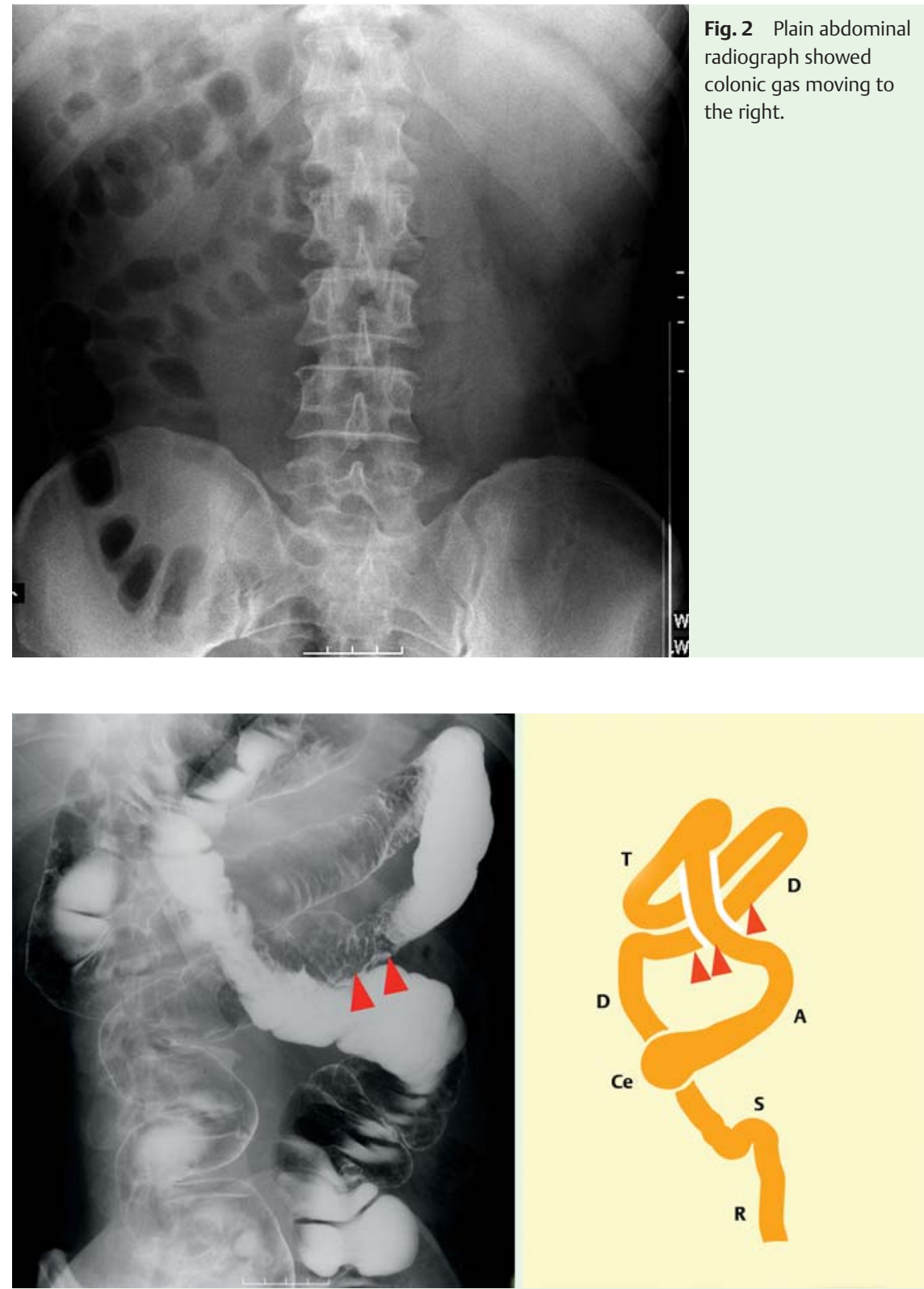

Fig. 3 a Contrast-enhanced irrigoscopy revealed transfer of the descending colon to the right through an area below the ascending colon, showing an abnormality in the intestinal course. The arrows indicate the continuity of a large number of polyp-like protrusions, suggesting the varix site. b Schematic diagram.

case of varices complicated by persistent mesocolon.

Persistent mesocolon is an anomaly that appears after 5 months of gestation, that is, during the developmental process. It is associated with the absence of fusion between the descending colon mesentery and posterior lateral parietal peritoneum.
The residual mesentery involves the splenic curvature to sigmoid colon in some cases $[4,5]$. In the present case, free movement to the right (has resulted in such a course. The patient had an anomaly in which the ascending colon was also not fixed. 


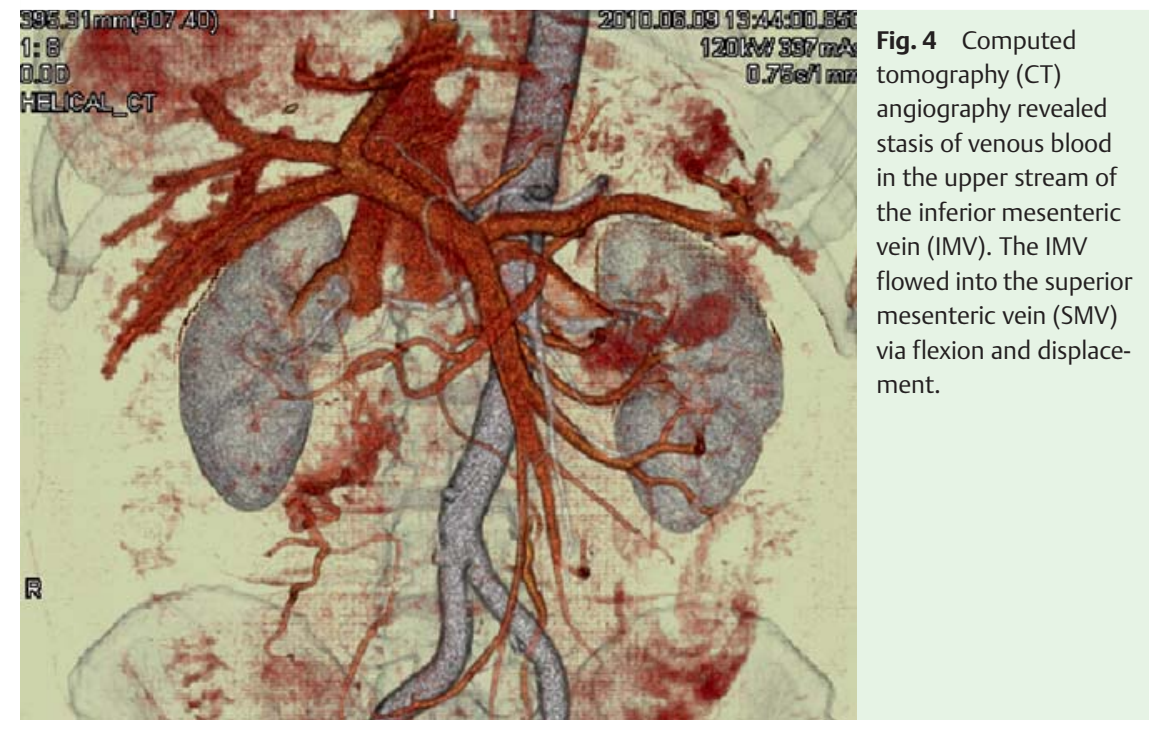

Concerning the pathogenesis of topical varices in the present case, a persistent mesocolon-related abnormality in the intestinal course may have induced local hypertension of the intestinal venous system of the descending colon, leading to varix formation.

\section{Acknowledgements \\ $\nabla$}

We thank Dr Akira Fujikawa and Dr Yukishige Kyoto for their help in the radiological examination of the patient.

Endoscopy_UCTN_Code_CCL_1AD_2AF

Competing interests: None

M. Kanai, T. Tokunaga, T. Miyaji, N. Mataki, C. Okada, K. Mitani, S. Aono, S. Kobari, Y. Hakozaki

Department of Internal Medicine, Division of Gastroenterology, Japan Self Defense Force Central Hospital, Tokyo, Japan

\section{References}

1 Feldman M Sr, Smith VM, Warner CG. Varices of the colon. Report of three cases. JAMA 1962; 179: 729-730

2 Han JH, Jeon WJ, Chae HB et al. A case of idiopathic colonic varices: a rare cause of hematochezia misconceived as tumor. World J Gastroenterol 2006; 12: 2629-2632

3 Zaman L, Bebb JR, Dunlop SP et al. Familial colonic varices - a cause of "popyposis" on barium enema. Br J Radiol 2008; 81: 17- 19

4 Popky GL, Lapayowker MS. Persistent descending mesocolon. Radiology 1966; 86: 327-331

5 Balthazar EJ. Congenital positional anomalies of the colon. Gastrointest Radiol 1977; 2: $49-56$

\section{Bibliography}

DOI $10.1055 / \mathrm{s}-0030-1256137$

Endoscopy 2011; 43: E103-E104

(c) Georg Thieme Verlag KG Stuttgart · New York . ISSN 0013-726X

\section{Corresponding author}

\section{Kanai, MD}

Department of Internal Medicine

Division of Gastroenterology

Japan Self Defence Force Central Hospital

1-2-24 lkejiri

Setagaya

Tokyo

Japan

Fax: +81-3-3418-0030

QYP00660@nifty.ne.jp 